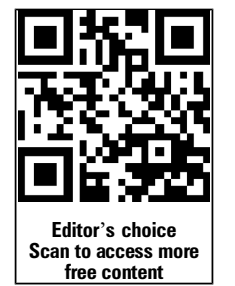
Promotion, Social and Behavioral Health, College of Public Health, University of Nebraska Medical Center, Omaha, Nebraska, USA ${ }^{2}$ Division of Epidemiology, U.S. Department of Health and Human Services, Health Resources and Services Administration (HRSA)/ Maternal and Child Health Bureau, Rockville, Maryland, USA

${ }^{3}$ Gretchen Swanson Center for Nutrition, University of Nebraska Medical Center, Omaha, Nebraska, USA

\section{Correspondence to} Dr Mohammad Siahpush, Department of Health Promotion, Social and Behavioral Health, College of Public Health, University of Nebraska Medical Center, 984365 Nebraska Medical Center, Omaha, NE 68198-4365, USA; msiahpush@unmc.edu

Received 26 November 2012 Accepted 13 March 2013 Published Online First 10 April 2013

\title{
It is better to be a fat ex-smoker than a thin smoker: findings from the 1997-2004 National Health Interview Survey-National Death Index linkage study
}

\author{
Mohammad Siahpush, ${ }^{1}$ Gopal K Singh, ${ }^{2}$ Melissa Tibbits, ${ }^{1}$ Courtney A Pinard, ${ }^{3}$ \\ Raees A Shaikh, ${ }^{1}$ Amy Yaroch ${ }^{3}$
}

\begin{abstract}
Objective The aim of this research was to compare the risk of all-cause mortality and mortality from all cancers combined, lung cancer, respiratory diseases, cardiovascular diseases and diabetes mellitus between normal-weight smokers and overweight or obese exsmokers.
\end{abstract}

Methods Data were from 1997 to 2004 National Health Interview Survey (with response rates ranging from $70 \%$ to $80 \%$ ) which were linked to records in the National Death Index. Mortality follow-up was through 31 December 2006. The sample was limited to normalweight smokers and overweight/obese ex-smokers 25 years of age and older ( $n=52819)$. HR from Cox regression was computed to represent mortality effect. Results Results showed that in both women and men, normal-weight smokers, relative to overweight or obese ex-smokers, had a higher risk of mortality from all causes combined, all cancers combined, lung cancer, cardiovascular and respiratory diseases. Among women, there was no difference in mortality risk from diabetes mellitus between normal-weight smokers and overweight or obese ex-smokers. Among men, there was some evidence that the risk of mortality was higher in obese ex-smokers than normal-weight smokers.

Conclusions This article concludes that, overall, mortality risk is smaller in overweight or obese exsmokers than normal-weight smokers. Smoking cessation interventions can tailor messages that highlight the greater reduction in mortality associated with quitting, compared with potential weight gain.

\section{INTRODUCTION}

Each year in the USA, smoking causes over 443000 deaths, primarily from cancer and cardiovascular and respiratory diseases. ${ }^{1}$ There is also mounting evidence that smoking increases the risk of and mortality from diabetes mellitus. ${ }^{2}{ }^{3}$ Fortunately, smoking cessation reduces risk of disease $^{4}$ and mortality from lung cancer, respiratory and cardiovascular diseases. ${ }^{5-9}$ However, smoking cessation is associated with weight gain. ${ }^{10-13}$ On average, smokers tend to weigh less than nonsmokers $^{12} 14$ and the majority of quitters gain about $3-9 \mathrm{~kg}$ within 8 years of quitting, ${ }^{15} 16$ and between $10 \%$ and $13 \%$ of quitters gain at least $11 \mathrm{~kg} .{ }^{11}$ Most of this weight gain occurs within 3 months of abstinence. ${ }^{17}$ Only a quarter of smokers maintain a healthy weight after quitting smoking. ${ }^{15}$ Consequently, postcessation weight gain is commonly cited, especially among women, as the main reason for not trying to quit. ${ }^{18}$ Similarly, about half of the smokers who have tried to quit but failed report that weight gain was the reason for their relapse. ${ }^{14}$

Weight gain also puts ex-smokers at risk of diseases that are caused by overweight and obesity. Overweight (defined as body mass index (BMI) of $25-29.9 \mathrm{~kg} / \mathrm{m}^{2}$ ) and obesity (defined as BMI of greater than or equal to $30 \mathrm{~kg} / \mathrm{m}^{2}$ ) are associated with higher risk of mortality from diabetes mellitus, various types of cancer, cardiovascular disease and respiratory diseases. ${ }^{19-23}$ Thus, the weight gain that results from smoking cessation may increase the risk of some of the same diseases whose risks are reduced by smoking cessation. This raises the question of which is least detrimental to health: to remain a normal-weight smoker or to quit smoking and possibly become an overweight/obese ex-smoker? In a study that examined the combined effect of smoking and BMI on all-cause mortality among older adults, Koster $e t a l^{24}$ found that the risk of mortality is higher in normal-weight smokers than overweight or obese ex-smokers. However, in a study of radiological technologists, Freedman et $a l^{25}$ did not find any difference in all-cause, cancer or cardiovascular disease mortality between normal-weight smokers and overweight or obese ex-smokers. To our knowledge, there are no studies based on a nationally representative sample that examine how the risk of morality from all causes combined as well as specific causes is different between normal-weight smokers and overweight/obese ex-smokers. Our aim was to compare the risk of all-cause mortality and mortality from all cancers combined, lung cancer, respiratory diseases, cardiovascular diseases, and diabetes mellitus between normal-weight smokers and overweight/ obese ex-smokers using data from the 1997 to 2004 National Health Interview Survey (NHIS) which has been linked to the National Death Index (NDI).

\section{METHODS}

\section{Data}

We employed public use data from the NHIS files for the years 1997-2004 and the corresponding files with the linkage of NHIS and NDI provided by the National Center for Health Statistics (NCHS). ${ }^{26}$ The NHIS is conducted annually, uses a multistage probability sampling design and is representative of the civilian non-institutional population of the USA. The annual response rate in the years 
1997-2004 ranged between 70\% and 80\%. All data are based on self-reports, including height, weight and smoking status information, and obtained via inhome interviews. Substantive and methodological details of the NHIS are described elsewhere. $^{26}$ The NCHS has linked the survey participants for the years 1986-2004 to death certificate data from the NDI with follow-ups through 31 December 2006. Mortality ascertainment is based on a probabilistic matching algorithm that links the NHIS and NDI records by an individual's social security number, name and other demographic variables. ${ }^{27}$ We limited the analysis to individuals who were aged 25 years and older and were either normal-weight smokers or overweight/obese ex-smokers, as defined below, at the time of the interview. The reason we have not included individuals under the age of 25 years is that there were too few deaths among this age group. For example, there were no deaths from lung cancer, respiratory diseases, cardiovascular diseases or diabetes mellitus among men in this age group.

\section{Measurement}

The outcomes were all-cause mortality, and morality from all cancers combined, lung cancer, respiratory diseases including chronic obstructive pulmonary disease (COPD), cardiovascular diseases and diabetes mellitus. The causes of death were coded according to the tenth revision of International Classification of Diseases (ICD-10). ${ }^{28}$ ICD-10 codes for the study outcomes are as follows: all cancers, C00-D48; lung cancer, C33-C34; respiratory disease/COPD, J00-J99; cardiovascular diseases I00-I99; and diabetes mellitus, E10-E14. Follow-up time for individuals who died was measured in number of months from the month/year of the interview to the month/year of death. Because quarter instead of month of death was available, we made the assumption that death occurred in the middle of the recorded quarter, that is, February, May, August or November.

The predictor of interest was normal-weight smoker versus overweight or obese ex-smoker. BMI was computed as the ratio of self-reported weight in kilograms divided by the square of self-reported height in metres. A BMI of greater than or equal to 18.5 and smaller than $25 \mathrm{~kg} / \mathrm{m}^{2}$ was considered normal weight; a BMI of equal to or higher than 25 and smaller than $30 \mathrm{~kg} / \mathrm{m}^{2}$ was considered overweight; and a BMI of greater than or equal to $30 \mathrm{~kg} / \mathrm{m}^{2}$ was considered obese. Smokers who were underweight (BMI $<18.5 \mathrm{~kg} / \mathrm{m}^{2}$ ) were excluded from the sample.

Respondents were asked 'Have you smoked at least 100 cigarettes in your entire life?' Those who replied affirmatively were then asked 'Do you now smoke cigarettes every day, some days or not at all?' Based on these questions, we defined smokers as those who have smoked at least 100 cigarettes in their life and currently smoked every day or some days, and ex-smokers as those who have smoked more than a 100 cigarettes in their life but do not currently smoke. Never-smokers, that is, those who have not smoked more than a 100 cigarettes in their life, were excluded from the analysis.

The sociodemographic predictors in the analyses were as follows: age, grouped into 25-44, 45-64 and 65+ years; marital status, grouped into married, separated/divorced, widowed and single; race/ethnicity, categorised as non-Hispanic white, non-Hispanic black, Hispanic and other; nativity, distinguishing those born in a US state or District of Colombia from others; educational attainment, grouped into 0-11, 12, 13-15 and $\geq 16$ years; family poverty status, measured as the ratio of total family income from all sources before taxes to the poverty threshold for each survey year; homeownership, distinguishing homeowners/purchasers from renters; and region of residence, grouped into Northeast, Midwest, South and West.

\section{Statistical analyses}

The data for all the survey years, that is, 1997-2004, along with information about mortality outcomes were pooled into one dataset. We computed age-standardised mortality rates per 100000 person years by sex among normal-weight smokers and overweight/obese ex-smokers for all-cause mortality and each of the specific causes of death that are the focus of the study. We used the direct method of age-standardisation based on the age distribution of the 2000 US Standard Population and employing the age categories $25-44,45-64$ and $65+.^{29}$

Cox proportional hazards regression was used to model time to death as a function of normal-weight smoker versus overweight/obese ex-smoker and sociodemographic predictors. We constructed survival curves based on covariate-adjusted regression results. In the analysis for a given cause of death, individuals who did not die of that cause as well as those surviving at the end of the follow-up were right-censored. Because we found strong evidence $(p<0.001)$ of an interaction between sex and normal-weight smoker versus overweight/obese ex-smoker, we stratified the regression models by sex. In all analyses, we adjusted for the complex sampling design of the NHIS by taking into account sampling weights provided in the NHIS-NDI linked mortality files, stratification and primary sampling units in computations. We adjusted the sampling weights by dividing them by 8 , the number of survey years used in the analysis. ${ }^{26}$ In addition, although our sample is restricted to the subpopulation of normal-weight smokers and overweight/obese ex-smokers, we have taken into account the full complex design of the sample in computing SEs. Thus, information on all clusters and strata, which is necessary for correct variance estimation, was included in the computations. Cases with missing values for any of the study variables (ie, $0.8 \%$ of the sample), except poverty status, were excluded from the analysis. Missing values for poverty status $(18.9 \%)$ were included as a distinct category. In addition, cases with insufficient data for linking NHIS and NDI records $(6.2 \%)$ were not included in the analysis. The final sample size for the analysis was 52819 (see figure 1). Stata SE V.12 was used in all analyses. ${ }^{30}$

\section{RESULTS}

In the pooled sample of individuals 25 years of age and older, 9.3\% were normal-weight smokers with an average BMI of $22.3 \mathrm{~kg} / \mathrm{m}^{2}, 9.6 \%$ were overweight ex-smokers with an average BMI of $27.3 \mathrm{~kg} / \mathrm{m}^{2}$ and $6.3 \%$ were obese ex-smokers with an average BMI of $34.6 \mathrm{~kg} / \mathrm{m}^{2}$. Table 1 shows the distribution of sociodemographic variables by sex among normal-weight smokers, overweight ex-smokers and obese ex-smokers. Among both men and women, normal-weight smokers were more likely than overweight/obese ex-smokers to be younger, unmarried, less educated, impoverished and to live in rented housing $(\mathrm{p}<0.001$ for all associations). Among both women and men, obese ex-smokers were more likely to be native to the USA than normal-weight smokers or overweight ex-smokers $(p=0.004$ in women and $\mathrm{p}<0.001$ in men).

Table 2 shows the number of deaths and age-adjusted mortality rates per 100000 person-years by subgroup. The total number of deaths was 5135. All mortality rates were substantially larger in normal-weight smokers than overweight or obese ex-smokers, except in the case of diabetes mellitus where there was little evidence to suggest a difference in the mortality rates. Among women, the overall age-adjusted mortality rate for 


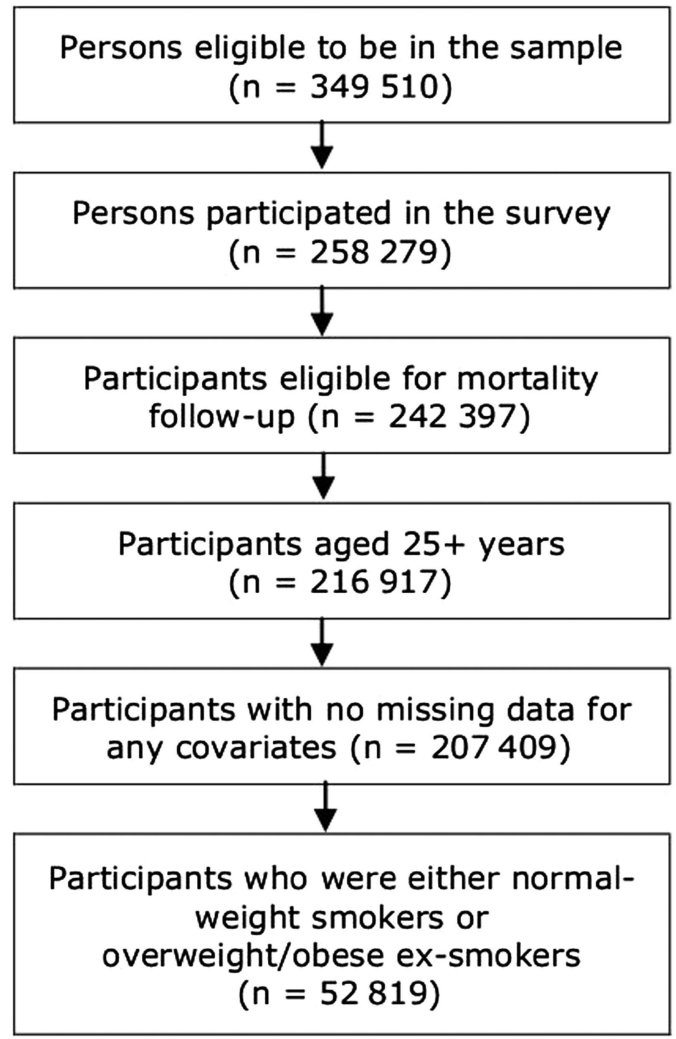

Figure 1 Flow diagram describing the final analysis sample size.

normal-weight smokers was 1668 (95\% CI 1552 to 1783), for overweight ex-smokers was 1093 (95\% CI 1009 to 1179) and for obese ex-smokers was 1222 (95\% CI 1118 to 1327) per 100000 person-years. Similarly, among men, the overall age-adjusted mortality rate for normal-weight smokers was 2809 (95\% CI 2627 to 2991), for overweight ex-smokers the rate was 1346 (95\% CI 1274 to 1417) and for obese ex-smokers the rate was 1523 (95\% CI 1411 to 1634) per 100000 person-years.

Tables 3 and 4 present age-adjusted and covariate-adjusted HRs for normal-weight smokers relative to overweight and obese ex-smokers from Cox proportional hazards regression models for women and men, respectively. Among women, the overall mortality risk was $26 \%$ lower in overweight and obese ex-smokers than normal-weight smokers $(\mathrm{p}<0.001)$. Among women, compared with normal-weight smokers, the risk of mortality from all cancers combined was $29 \%$ and $46 \%$ lower in overweight and obese ex-smokers, respectively $(\mathrm{p}<0.001)$. A similar pattern of risk difference existed in the case of lung cancer $(59 \%$ and $79 \%, \mathrm{p}<0.001)$, respiratory diseases $(44 \%$ and $36 \%, \mathrm{p}<0.001)$ and cardiovascular diseases $(26 \%$ and $21 \%, \mathrm{p}=0.013)$. Among men, compared with normal-weight smokers, the overall mortality risk was $41 \%$ and $37 \%$ lower in overweight and obese ex-smokers, respectively $(\mathrm{p}<0.001)$. A similar pattern of risk difference existed in the case of all cancers combined $(31 \%$ and $33 \%, \mathrm{p}<0.001)$, lung cancer $(70 \%$ and $75 \%, \mathrm{p}<0.001)$, respiratory diseases $(65 \%$ and $65 \%$, $\mathrm{p}<0.001)$ and cardiovascular diseases $(25 \%$ and $15 \%$, $\mathrm{p}=0.009)$. Compared with normal-weight smokers, the risk of mortality from diabetes mellitus was $4 \%$ and $98 \%$ higher in overweight and obese ex-smokers, respectively $(p=0.011)$. We note that the observed effects on mortality were stronger for men than women, except in the case of mortality from cardiovascular diseases. We also note that we examined the change in the coefficients and their SEs in the main predictor, normal-weight smoker versus overweight ex-smoker versus obese ex-smoker, before and after other covariates were added to the models. We have found no evidence of a drastic change to suggest multicollinearity is a problem in the current analysis.

Figures 2 and 3 show survival curves for each cause of death for women and men, respectively. Consistent with the findings presented above, these curves clearly indicate a survival advantage for overweight and obese ex-smokers for all-cause mortality and mortality from selected causes. The survival curves for diabetes mellitus among women are not shown, as the regression results did not indicate a mortality difference between normalweight smokers and overweight or obese ex-smokers.

In supplementary analyses not shown, we found that the covariate-adjusted risk of mortality from all causes combined and from specific causes (except diabetes mellitus) was greater in normal-weight smokers than overweight never-smokers or obese never-smokers. There was no difference in risk of mortality from diabetes mellitus. In additional supplementary analyses for each specific disease, we excluded the baseline respondents who had indicated they had been diagnosed with that disease. The only notable difference from the results reported above was that there was no effect of the exposure on mortality from diabetes mellitus among men.

\section{DISCUSSION}

This nationally representative study provided strong evidence that the risk of mortality from all causes combined, all cancers combined, lung cancer, respiratory diseases and cardiovascular diseases is higher in normal-weight smokers than overweight/ obese ex-smokers. It is important to note that the magnitude of this increased risk was larger among men than women for allcause mortality and mortality from all cancers combined, lung cancer and respiratory disease. In contrast, the magnitude of the increased risk was larger among women in the case of mortality from cardiovascular diseases.

Our finding that normal-weight smokers had a higher risk of all-cause mortality than overweight/obese ex-smokers was in accordance with the report of Koster et $a l^{24}$ on older adults. However, our findings in relation to cause-specific mortality were not consistent with the results of Freedman et $a l^{25}$ that among radiological technologists being a normal-weight smoker versus an overweight/obese ex-smoker does not affect the risk of mortality from cancer or cardiovascular disease. The inconsistency may be due to the Freedman et al sample which was limited to one occupational group, was over 90\% white, and thus did not represent the general population.

We found that among men, there is some evidence that the risk of mortality from diabetes mellitus is higher in overweight or obese ex-smokers than normal-weight smokers. However, such an effect was not observed among women. Previous studies have shown that while smoking cessation is associated with a higher risk of diabetes, ${ }^{3} 3132$ the increased risk diminishes with time and disappears after 12 years. ${ }^{3}$ Furthermore, a prospective study with a follow-up of 8.5 years found that there was an increased risk of diabetes associated with quitting among those women who gained at least $5 \mathrm{~kg}$. $^{33}$

A major strength of our study was the use of a large, nationally representative sample with high response rates and a data collection based on inperson home interviews. The mortality rates presented in table 2 are reasonably valid as the NHIS-NDI based mortality rates for the general population aged $25+$ years compare well with those derived from the national vital statistics 
Table 1 Weighted sample characteristics (\%) by sex among normal-weight smokers and overweight ex-smokers and obese ex-smokers $(\mathrm{n}=52819)$

\begin{tabular}{|c|c|c|c|c|c|c|}
\hline \multirow[b]{2}{*}{ Characteristics } & \multicolumn{3}{|l|}{ Women } & \multicolumn{3}{|l|}{ Men } \\
\hline & $\begin{array}{l}\text { Normal-weight } \\
\text { smokers }\left(n^{*}=11371\right)\end{array}$ & $\begin{array}{l}\text { Overweight } \\
\text { ex-smokers } \\
(n=6846)\end{array}$ & $\begin{array}{l}\text { Obese } \\
\text { ex-smokers } \\
(n=6107)\end{array}$ & $\begin{array}{l}\text { Normal-weight } \\
\text { smokers }(n=8996)\end{array}$ & $\begin{array}{l}\text { Overweight } \\
\text { ex-smokers } \\
(\mathrm{n}=12583)\end{array}$ & $\begin{array}{l}\text { Obese } \\
\text { ex-smokers } \\
(n=6916)\end{array}$ \\
\hline \multicolumn{7}{|l|}{ Age } \\
\hline $25-44$ & 55.79 & 24.93 & 29.46 & 56.1 & 24.8 & 24.85 \\
\hline $45-64$ & 33.09 & 43.07 & 45.36 & 34.9 & 44.28 & 50.45 \\
\hline $65+$ & 11.11 & 31.99 & 25.17 & 9.00 & 30.92 & 24.7 \\
\hline \multicolumn{7}{|l|}{ Marital status } \\
\hline Married & 52.79 & 62.21 & 58.47 & 52.29 & 77.93 & 79.11 \\
\hline Divorced/separated & 25.41 & 14.77 & 17.85 & 21.67 & 10.24 & 10.48 \\
\hline Widowed & 8.55 & 16.76 & 14.56 & 2.84 & 4.81 & 3.74 \\
\hline Never married & 13.25 & 6.25 & 9.11 & 23.2 & 7.02 & 6.67 \\
\hline \multicolumn{7}{|l|}{ Race/ethnicity } \\
\hline Non-Hispanic white & 85.19 & 83.9 & 77.24 & 75.23 & 83.64 & 81.56 \\
\hline Non-Hispanic black & 7.88 & 8.51 & 13.69 & 11.78 & 6.42 & 8.19 \\
\hline Hispanic & 4.68 & 6.2 & 7.57 & 7.71 & 7.58 & 8.25 \\
\hline Other & 2.25 & 1.38 & 1.5 & 5.28 & 2.36 & 2.00 \\
\hline \multicolumn{7}{|l|}{ Nativity } \\
\hline $\begin{array}{l}\text { Born in a US state or } \\
\text { District of Columbia }\end{array}$ & 93.26 & 92.33 & 94.01 & 87.26 & 89.42 & 91.77 \\
\hline Others & 6.74 & 7.67 & 5.99 & 12.74 & 10.58 & 8.23 \\
\hline \multicolumn{7}{|c|}{ Education (years of schooling completed) } \\
\hline $0-11$ & 15.47 & 14.75 & 18.63 & 21.34 & 15.28 & 18.6 \\
\hline 12 & 40.48 & 34.76 & 35.01 & 39.66 & 31.05 & 33.59 \\
\hline $13-15$ & 29.68 & 29.95 & 31.41 & 25.55 & 27.44 & 28.00 \\
\hline $16+$ & 14.37 & 20.54 & 14.95 & 13.46 & 26.23 & 19.81 \\
\hline \multicolumn{7}{|c|}{ Poverty status (ratio of family income to poverty threshold) } \\
\hline$<100 \%$ & 11.12 & 5.65 & 9.26 & 10.84 & 3.56 & 4.97 \\
\hline$\geq 100 \%$ and $<200 \%$ & 15.42 & 13.425 & 16.35 & 18.04 & 10.51 & 11.85 \\
\hline$\geq 200 \%$ and $<300 \%$ & 14.6 & 13.29 & 15.69 & 16.62 & 13.01 & 14.39 \\
\hline$\geq 300 \%$ and $<400 \%$ & 12.49 & 11.8 & 12.69 & 12.92 & 12.85 & 12.62 \\
\hline$\geq 400$ & 27.44 & 34.2 & 26.09 & 24.75 & 39.19 & 37.64 \\
\hline $\begin{array}{l}\text { No income } \\
\text { information }\end{array}$ & 18.93 & 21.63 & 19.92 & 16.84 & 20.88 & 18.52 \\
\hline \multicolumn{7}{|l|}{ Home ownership } \\
\hline Renter & 30.98 & 18.00 & 23.96 & 37.47 & 14.47 & 14.81 \\
\hline Owner/purchaser & 69.02 & 82.00 & 76.04 & 62.53 & 85.53 & 85.19 \\
\hline \multicolumn{7}{|l|}{ Region } \\
\hline Northeast & 20.23 & 22.87 & 19.78 & 17.24 & 20.92 & 20.11 \\
\hline North central/Midwest & 26.88 & 25.11 & 28.31 & 26.36 & 25.5 & 25.86 \\
\hline South & 37.02 & 33.52 & 34.01 & 39.16 & 34.53 & 36.51 \\
\hline West & 15.87 & 18.5 & 17.9 & 17.25 & 19.05 & 17.52 \\
\hline
\end{tabular}

${ }^{*}$ Sample sizes are not weighted.

mortality rates for the period 1997-2004. For example, in the NHIS-NDI database, the age-adjusted all-cause mortality rate was 1690 per 100000 population in men and 1200 per 100000 population in women; the corresponding age-adjusted vital statistics based mortality rates were 1560 in men and 1076 in women. ${ }^{29}$

Our study had some possible limitations. We were unable to assess changes in smoking or overweight or obesity status during the follow-up period; thus, the exposure was assumed to be time-invariant. Similarly, we did not have information on duration of abstinence from smoking. Furthermore, smoking status, height and weight were self-reported and not based on objective measurement. However, self-reported smoking status in surveys of the general population has been validated with cotinine ${ }^{34}$ and the amount of misclassification (ie, proportion of selfreported non-smokers with increased cotinine levels indicative of active smoking) is very low (eg, $0.9 \% 0^{35}$ and $1.4 \%{ }^{36}$ ) in most community based studies. ${ }^{37}$ People who are overweight or obese are more likely than others to underestimate their weight and overestimate their height. ${ }^{38}$ This suggests that the group of overweight/obese ex-smokers in our study was possibly larger than we estimated and we did not include some ex-smokers at the lower end of the overweight/obesity continuum. This might have resulted in a slight overestimation of the effects reported in this study.

Another limitation of the study was that we were unable to use graded obesity classes as defined by WHO: class I (BMI $\geq 30.0$ and $<35$ ), class II $(\mathrm{BMI} \geq 35.0$ and $<40)$ and class III 
Table 2 Number of deaths and age-adjusted mortality rates per 100000 person years and $95 \%$ Cls by sex among normal-weight smokers and overweight and obese ex-smokers ( $n=52819)$

\begin{tabular}{|c|c|c|c|c|c|c|}
\hline \multirow[b]{2}{*}{ Cause of death } & \multicolumn{3}{|l|}{ Women (n=24 324) } & \multicolumn{3}{|l|}{ Men (28 495) } \\
\hline & $\begin{array}{l}\text { Normal-weight } \\
\text { smokers }\end{array}$ & $\begin{array}{l}\text { Overweight } \\
\text { ex-smokers }\end{array}$ & $\begin{array}{l}\text { Obese } \\
\text { ex-smokers }\end{array}$ & $\begin{array}{l}\text { Normal-weight } \\
\text { smokers }\end{array}$ & $\begin{array}{l}\text { Overweight } \\
\text { ex-smokers }\end{array}$ & $\begin{array}{l}\text { Obese } \\
\text { ex-smokers }\end{array}$ \\
\hline \multicolumn{7}{|l|}{ All causes } \\
\hline Number of deaths & 810 & 670 & 535 & 966 & 1417 & 737 \\
\hline Age-adjusted mortality rate & 1668 (1552-1783) & 1093 (1009-1179) & $1222(1118-1327)$ & 2809 (2627-2991) & 1346 (1274-1417) & $1523(1411-1634)$ \\
\hline \multicolumn{7}{|l|}{ All cancers combined } \\
\hline Number of deaths & 261 & 198 & 127 & 319 & 434 & 638 \\
\hline Age-adjusted mortality rate & $534(468-600)$ & $347(296-398)$ & $290(239-341)$ & $943(834-1052)$ & $415(375-456)$ & $413(356-471)$ \\
\hline \multicolumn{7}{|l|}{ Lung cancer } \\
\hline Number of deaths & 141 & 64 & 37 & 159 & 133 & 57 \\
\hline Age-adjusted mortality rate & $294(244-344)$ & $106(80-133)$ & $80(54-106)$ & $475(397-554)$ & $122(101-143)$ & $115(85-145)$ \\
\hline \multicolumn{7}{|l|}{ Respiratory diseases } \\
\hline Number of deaths & 116 & 76 & 66 & 111 & 138 & 53 \\
\hline Age-adjusted mortality rate & $250(203-296)$ & $119(92-146)$ & $146(110-181)$ & $374(301-446)$ & $124(103-145)$ & $108(79-138)$ \\
\hline \multicolumn{7}{|l|}{ Cardiovascular diseases } \\
\hline Number of deaths & 255 & 238 & 200 & 266 & 507 & 299 \\
\hline Age-adjusted mortality rate & $553(484-622)$ & $377(328-426)$ & $453(389-517)$ & $815(712-918)$ & $467(426-509)$ & $601(533-669)$ \\
\hline \multicolumn{7}{|l|}{ Diabetes mellitus } \\
\hline Number of deaths & 20 & 31 & 36 & 26 & 46 & 43 \\
\hline Age-adjusted mortality rate & $39(22-57)$ & $51(32-70)$ & $83(55-111)$ & $72(42-102)$ & $45(31-58)$ & $86(60-113)$ \\
\hline
\end{tabular}

(BMI $\geq 40.0) .{ }^{39}$ This was because the number of deaths from lung cancer, respiratory diseases and diabetes mellitus were too few among individuals who were classified as class I $(5 \%$ of the sample) or II ( $3 \%$ of the sample) obese.
Our study suggests that although smoking cessation may result in overweight or obesity, this risk does not outweigh the benefits of smoking cessation in terms of reductions in mortality risks. Smoking cessation interventions can use this information

Table 3 Age-adjusted and covariate-adjusted* HRs for overweight and obese smokers relative to normal-weight smokers by cause of death among women $(n=24324)$

\begin{tabular}{|c|c|c|c|c|}
\hline Cause of death & Age-adjusted HR (95\% Cl) & $\mathrm{p}$ Value & Covariate-adjusted HR (95\% Cl) & p Value \\
\hline All causes & & $<0.001$ & & $<0.001$ \\
\hline Normal-weight smoker & 1.00 & & 1.00 & \\
\hline Overweight ex-smoker & 0.67 (0.59 to 0.76$)$ & & 0.74 (0.65 to 0.84 ) & \\
\hline Obese ex-smoker & 0.74 (0.64 to 0.85$)$ & & 0.74 (0.64 to 0.85$)$ & \\
\hline All cancers combined & & $<0.001$ & & $<0.001$ \\
\hline Normal-weight smoker & 1.00 & & 1.00 & \\
\hline Overweight ex-smoker & 0.67 (0.53 to 0.84$)$ & & 0.71 (0.56 to 0.89$)$ & \\
\hline Obese ex-smoker & $0.53(0.41$ to 0.70$)$ & & 0.54 (0.41 to 0.71$)$ & \\
\hline Lung cancer & & $<0.001$ & & $<0.001$ \\
\hline Normal-weight smoker & 1.00 & & 1.00 & \\
\hline Overweight ex-smoker & 0.39 (0.27 to 0.56$)$ & & 0.41 (0.28 to 0.58$)$ & \\
\hline Obese ex-smoker & 0.22 (0.14 to 0.32$)$ & & 0.21 (0.14 to 0.32 ) & \\
\hline Respiratory diseases & & $<0.001$ & & 0.002 \\
\hline Normal-weight smoker & 1.00 & & 1.00 & \\
\hline Overweight ex-smoker & $0.48(0.34$ to 0.69$)$ & & 0.56 (0.39 to 0.80$)$ & \\
\hline Obese ex-smoker & 0.62 (0.44 to 0.86$)$ & & 0.64 (0.46 to 0.90$)$ & \\
\hline Cardiovascular diseases & & 0.001 & & 0.013 \\
\hline Normal-weight smoker & 1.00 & & 1.00 & \\
\hline Overweight ex-smoker & 0.67 (0.55 to 0.83 ) & & 0.74 (0.60 to 0.91$)$ & \\
\hline Obese ex-smoker & 0.81 (0.64 to 1.01$)$ & & 0.79 (0.63 to 0.99$)$ & \\
\hline Diabetes mellitus & & 0.051 & & 0.269 \\
\hline Normal-weight smoker & 1.00 & & 1.00 & \\
\hline Overweight ex-smoker & 1.15 (0.60 to 2.19$)$ & & 1.29 (0.69 to 2.44$)$ & \\
\hline Obese ex-smoker & 1.98 (1.02 to 3.83$)$ & & 1.78 (0.87 to 3.63$)$ & \\
\hline
\end{tabular}

${ }^{*}$ Adjusted for age, marital status, race/ethnicity, nativity, education, poverty status, home ownership and region of residence. 
Table 4 Age-adjusted and covariate-adjusted* HRs for overweight and obese smokers relative to normal-weight smokers by cause of death among men $(n=28$ 495)

\begin{tabular}{|c|c|c|c|c|}
\hline Cause of death & Age-adjusted HR (95\% Cl) & $\mathrm{p}$ Value & Covariate-adjusted HR ( $95 \% \mathrm{CI})$ & $p$ Value \\
\hline All causes & & $<0.001$ & & $<0.001$ \\
\hline Normal-weight smoker & 1.00 & & 1.00 & \\
\hline Overweight ex-smoker & 0.47 (0.42 to 0.52$)$ & & 0.59 (0.53 to 0.66$)$ & \\
\hline Obese ex-smoker & 0.52 (0.46 to 0.59 ) & & 0.63 (0.56 to 0.72 ) & \\
\hline All cancers combined & & $<0.001$ & & $<0.001$ \\
\hline Normal-weight smoker & 1.00 & & 1.00 & \\
\hline Overweight ex-smoker & $0.42(0.35$ to 0.51$)$ & & $0.49(0.41$ to 0.60$)$ & \\
\hline Obese ex-smoker & $0.42(0.34$ to 0.52$)$ & & $0.47(0.38$ to 0.59$)$ & \\
\hline Lung cancer & & $<0.001$ & & $<0.001$ \\
\hline Normal-weight smoker & 1.00 & & 1.00 & \\
\hline Overweight ex-smoker & 0.25 (0.19 to 0.33$)$ & & $0.30(0.22$ to 0.39$)$ & \\
\hline Obese ex-smoker & $0.22(0.15$ to 0.31$)$ & & $0.25(0.17$ to 0.35$)$ & \\
\hline Respiratory diseases & & $<0.001$ & & $<0.001$ \\
\hline Normal-weight smoker & 1.00 & & 1.00 & \\
\hline Overweight ex-smoker & $0.29(0.22$ to 0.40$)$ & & $0.35(0.25$ to 0.48$)$ & \\
\hline Obese ex-smoker & $0.30(0.21$ to 0.43$)$ & & $0.35(0.24$ to 0.50$)$ & \\
\hline Cardiovascular diseases & & $<0.001$ & & 0.009 \\
\hline Normal-weight smoker & 1.00 & & 1.00 & \\
\hline Overweight ex-smoker & 0.57 (0.48 to 0.68$)$ & & $0.75(0.62$ to 0.90$)$ & \\
\hline Obese ex-smoker & 0.67 (0.56 to 0.82$)$ & & 0.85 (0.70 to 1.04$)$ & \\
\hline Diabetes mellitus & & 0.010 & & 0.011 \\
\hline Normal-weight smoker & 1.00 & & 1.00 & \\
\hline Overweight ex-smoker & $0.69(0.36$ to 1.30$)$ & & 1.04 (0.53 to 2.02$)$ & \\
\hline Obese ex-smoker & 1.41 (0.75 to 2.63 ) & & 1.98 (1.04 to 3.76$)$ & \\
\hline
\end{tabular}

${ }^{*}$ Adjusted for age, marital status, race/ethnicity, nativity, education, poverty status, home ownership and region of residence.

to tailor their messages to negate the fear of weight gain that may be associated with quitting smoking. These interventions should especially target women, given that they present weight gain as a major barrier to smoking cessation. ${ }^{18}$ In addition, further research on how smoking cessation interventions can best be paired with weigh gain prevention is warranted. ${ }^{40}$ Healthcare providers, health promotion programmes and public health professionals should advise their clients who smoke that
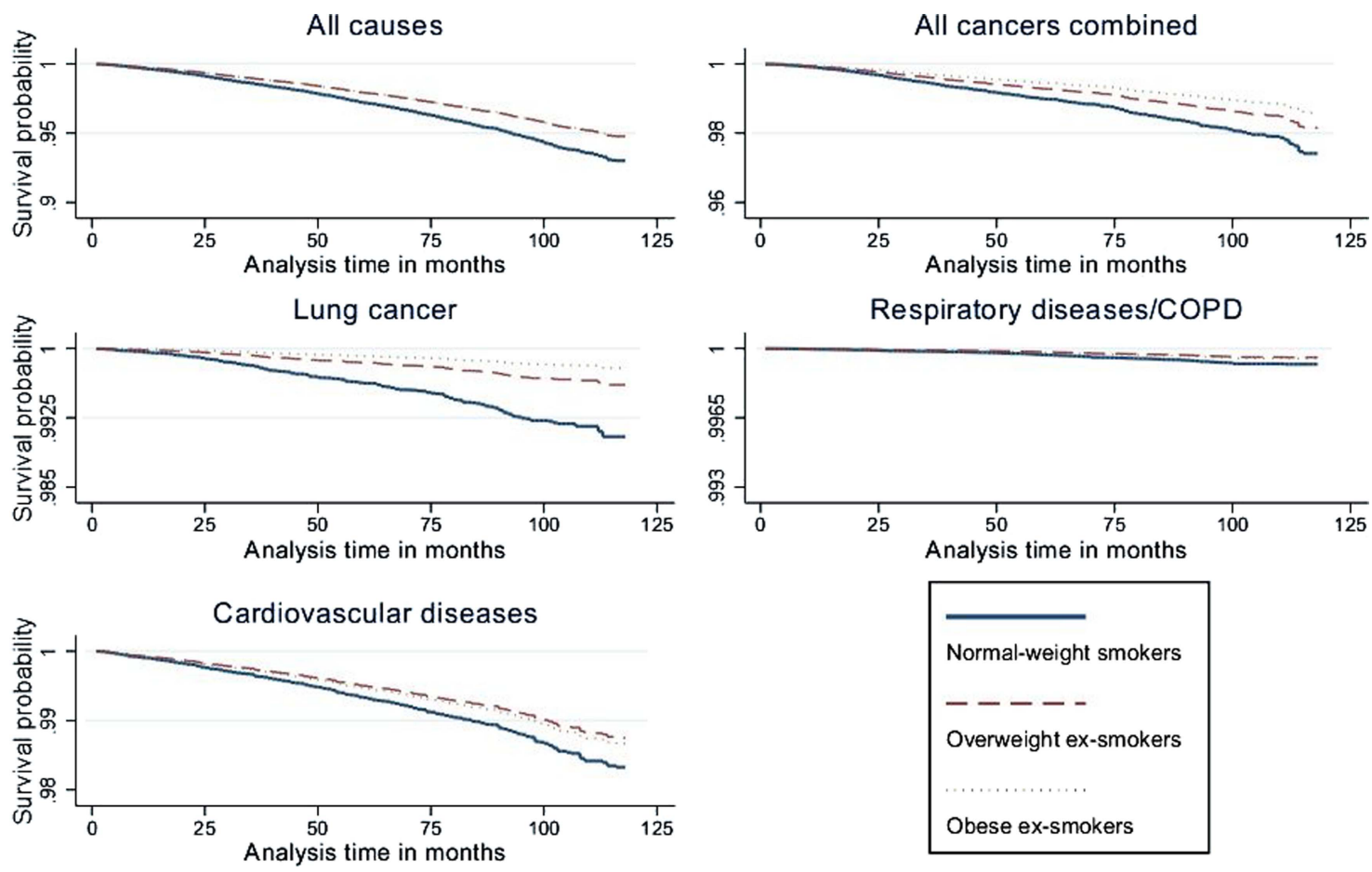

Figure 2 Survival curves for women by cause of death. COPD, chronic obstructive pulmonary disease. 

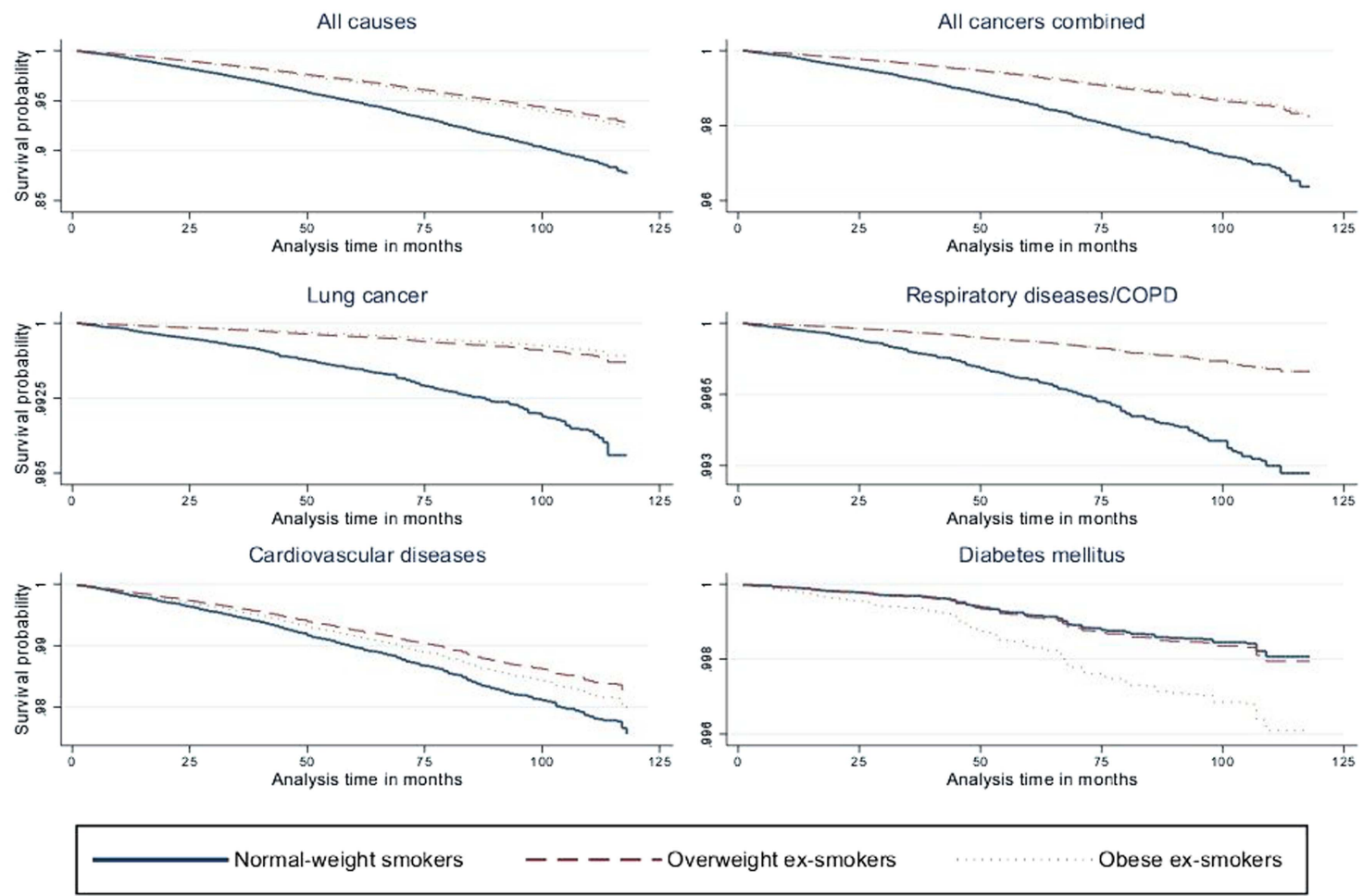

Figure 3 Survival curves for men by cause of death. COPD, chronic obstructive pulmonary disease.

even if they gain weight because of quitting, it is still a healthier option than continuing to smoke.

\section{What this paper adds}

- Our study used a large, nationally representative sample with high response rates to find that although smoking cessation may result in overweight or obesity, this risk does not outweigh the benefits of smoking cessation in terms of reductions in mortality risks.

- This information can be used by healthcare providers, health promotion programmes and public health professionals to plan and administer effective smoking cessation interventions.

- This knowledge could be used to tailor the smoking cessation messages to negate the fear of weight gain that may be associated with quitting smoking, especially among women.

Contributors We assure that all authors included on the paper fulfil the criteria of authorship. All have contributed to the conception and design, analysis and interpretation of data, drafting of the article and revising it critically for important intellectual content, and final approval of the version to be published. In addition, we also assure that there is no one else who fulfils the criteria but has not been included as an author.

Competing interests All authors have completed the Unified Competing Interest form (available on request from the corresponding author) and declare that no support was received from any organisation for the submitted work and that there were no financial relationships with any organisations that might have an interest in the submitted work in the previous 3 years; we did not have other relationships or activities that could appear to have influenced the submitted work.

Provenance and peer review Not commissioned; internally peer reviewed.

\section{REFERENCES}

1 Centers for Disease Control and Prevention (CDC). Smoking-attributable mortality, years of potential life lost, and productivity losses-United States, 2000-2004. MMWR 2008;57(45):1226-8.

2 Jee SH, Foong AW, Hur NW, et al. Smoking and risk for diabetes incidence and mortality in Korean men and women. Diabetes care 2010;33:2567-72.

3 Yeh HC, Duncan BB, Schmidt MI, et al. Smoking, smoking cessation, and risk for type 2 diabetes mellitus: a cohort study. Ann Intern Med 2010;152:10-17.

4 Centers for Disease Control and Prevention (US), National Center for Chronic Disease Prevention and Health Promotion (US), Office on Smoking and Health (US). How Tobacco Smoke Causes Disease-The Biology and Behavioral Basis for Smoking-Attributable Disease: A Report of the Surgeon General. 2010

5 Godtfredsen NS, Holst C, Prescott E, et al. Smoking reduction, smoking cessation, and mortality: a 16-year follow-up of 19,732 men and women from The Copenhagen Centre for Prospective Population Studies. Am J Epidemiol 2002;156:994-1001.

6 Iso H, Date C, Yamamoto A, et al. Smoking cessation and mortality from cardiovascular disease among Japanese men and women. Am J Epidemiol 2005;161:170-9.

7 Kawachi I, Colditz GA, Stampfer J, et al. Smoking cessation and time course of decreased risks of coronary heart disease in middle-aged women. Arch Intern Med 1994:154:169.

8 Godtfredsen NS, Prescott E, Osler M. Effect of smoking reduction on lung cancer risk. JAMA 2005;294:1505-10.

9 Godtfredsen N, Lam T, Hansel T, et al. COPD-related morbidity and mortality after smoking cessation: status of the evidence. Eur Respir J 2008;32:844-53.

10 Kasteridis P, Yen ST. Smoking cessation and body weight: evidence from the behavioral risk factor surveillance survey. Health Serv Res 2012;47:1580-602.

11 Williamson DF, Madans J, Anda RF, et al. Smoking cessation and severity of weight gain in a national cohort. N Engl I Med 1991;324:739-45.

12 Filozof C, Pinilla MC Fernandez, Fernandez-Cruz A. Smoking cessation and weight gain. Obe Rev 2004;5:95-103.

13 Klesges RC, Winders SE, Meyers AW, et al. How much weight gain occurs following smoking cessation: a comparison of weight gain using both continuous and point prevalence abstinence. J Consult Clin Psychol 1997;65:286

14 Pisinger $C$, Jorgensen $T$. Weight concerns and smoking in a general population: the Inter99 study. Prev Med 2007:44:283-9.

15 Lycett $D$, Munafò $M$, Johnstone $E$, et al. Associations between weight change over 8 years and baseline body mass index in a cohort of continuing and quitting smokers. Addiction 2011;106:188-96.

16 O'Hara P, Connett JE, Lee WW, et al. Early and late weight gain following smoking cessation in the Lung Health Study. Am J Epidemiol 1998;148:821-30. 
17 Aubin HJ, Farley $A$, Lycett $D$, et al. Weight gain in smokers after quitting cigarettes: meta-analysis. BMJ 2012;345:e4439.

18 Pomerleau CS, Zucker AN, Stewart AJ. Characterizing concerns about post-cessation weight gain: results from a national survey of women smokers. Nicotine Tobacco Res 2001:3:51-60.

19 Calle EE, Rodriguez C, Walker-Thurmond K, et al. Overweight, obesity, and mortality from cancer in a prospectively studied cohort of US adults. N Engl J Med 2003;348:1625-38

20 Wei M, Kampert JB, Barlow CE, et al. Relationship between low cardiorespiratory fitness and mortality in normal-weight, overweight, and obese men. JAMA 1999;282:1547-53.

21 Flegal KM, Graubard BI, Williamson DF, et al. Cause-specific excess deaths associated with underweight, overweight, and obesity. JAMA 2007;298:2028-37.

22 McGee DL, Collaboration DP. Body mass index and mortality: a meta-analysis based on person-level data from twenty-six observational studies. Ann Epidemiol 2005; 15:87-97.

23 Prospective Studies Collaboration. Body-mass index and cause-specific mortality in 900000 adults: collaborative analyses of 57 prospective studies. Lancet 2009;373:1083-96.

24 Koster A, Leitzmann MF, Schatzkin A, et al. The combined relations of adiposity and smoking on mortality. Am J Clin Nutr 2008:88:1206-12.

25 Freedman DM, Sigurdson AJ, Rajaraman $\mathrm{P}$, et al. The mortality risk of smoking and obesity combined. Am J Prev Med 2006;31:355-62.

26 National Center for Health Statistics, Centers for Disease Control and Prevention. National Health Interview Survey. 2012; (July 2012).

27 National Center for Health Statistics. The National Health Interview Survey (1986-2004) Linked Mortality Files, mortality follow-up through 2006: Matching Methodology. Hyattsville, Maryland: National Center for Health Statistics, 2009.
28 World Health Organization. International statistical classification of diseases and related health problems, tenth revision. Geneva: World Health Organization, 1992.

29 Minino AM, Murphy SL, Xu J, et al. Deaths: final data for 2008. Nat/ Vital Stat Rep 2011:59:1-152

30 Stata C. Stata Statistical Software: Release 12, Special Edition. 2011.

31 Wannamethee SG, Shaper AG, Perry IJ, et al. Smoking as a modifiable risk factor for type 2 diabetes in middle-aged men. Diabetes Care 2001;24:1590-5.

32 Hur NW, Kim HC, Nam CM, et al. Smoking cessation and risk of type 2 diabetes mellitus: Korea Medical Insurance Corporation Study. Eur J Cardiovasc Prev Rehabil 2007:14:244-9.

33 Luo J, Rossouw J, Tong E, et al. Smoking cessation, weight gain, and risk of type 2 diabetes mellitus among postmenopausal women. Arch Intern Med 2012;172:438-40.

34 Vartiainen E, Seppala T, Lillsunde $P$, et al. Validation of self reported smoking by serum cotinine measurement in a community-based study. J Epidemiol Community Health 2002;56:167-70

35 Wald N, Nanchahal K, Thompson S, et al. Does breathing other people's tobacco smoke cause lung cancer? BMJ 1986;293:1217-22.

36 Caraballo R, Giovino G, Pechacek T, et al. Factors associated with discrepancies between self-reports on cigarette smoking and measured serum cotinine levels among persons aged 17 years or older: Third National Health and Nutrition Examination survey, 1988-1994. Am J Epidemiol 2001:153:807-14.

37 Rebagliato M. Validation of self reported smoking: the use of cotinine as a biomarker for exposure to smoking. J Epidemiol Community Health 2002;56:163-4.

38 Rowland ML. Self-reported weight and height. Am J Clin Nutr 1990;52:1125-33.

39 World Health Organization. Measuring obesity: classification and description of anthropometric data. Copenhagen: WHO, 1989:12-17.

40 Parsons AC, Shraim M, Inglis J, et al. Interventions for preventing weight gain after smoking cessation. Cochrane Database Syst Rev 2009;(1):CD006219. 